\title{
Chronic intermittent hypoxia increases rat sternohyoid muscle NADPH oxidase expression with attendant modest oxidative stress
}

\author{
Robert Williams ${ }^{1}$, Paul Lemaire ${ }^{1}$, Philip Lewis ${ }^{1}$, Fiona B. McDonald ${ }^{2}$, Eric Lucking ${ }^{2}$, Sean Hogan ${ }^{1}$, \\ David Sheehan ${ }^{3}$, Vincent Healy ${ }^{1}$ and Ken D. O'Halloran ${ }^{1 *}$
}

${ }^{1}$ Department of Physiology, School of Medicine, University College Cork, Cork, Ireland

${ }^{2}$ School of Medicine and Medical Science, University College Dublin, Dublin, Ireland

${ }^{3}$ School of Biochemistry and Cell Biology, University College Cork, Cork, Ireland

\section{Edited by:}

Brian McDonagh, University of

Liverpool, UK

Reviewed by:

Nazareno Paolocci, Johns Hopkins

University, USA

Cecilia Hidalgo, Universidad de

Chile, Chile

*Correspondence:

Ken D. O'Halloran, Department of Physiology, School of Medicine,

University College Cork, 3-079,

Western Gateway Building, Western

Road, Cork, Ireland

e-mail:k.ohalloran@ucc.ie
Chronic intermittent hypoxia $(\mathrm{ClH})$ causes upper airway muscle dysfunction. We hypothesized that the superoxide generating NADPH oxidase (NOX) is upregulated in $\mathrm{ClH}$-exposed muscle causing oxidative stress. Adult male Wistar rats were exposed to intermittent hypoxia ( $5 \% \mathrm{O}_{2}$ at the nadir for $90 \mathrm{~s}$ followed by $210 \mathrm{~s}$ of normoxia), for $8 \mathrm{~h}$ per day for 14 days. The effect of $\mathrm{ClH}$ exposure on the expression of NOX subunits, total myosin and 4-hydroxynonenal (4-HNE) protein adducts in sternohyoid muscle was determined by western blotting and densitometry. Sternohyoid protein free thiol and carbonyl group contents were determined by 1D electrophoresis using specific fluorophore probes. Aconitase and glutathione reductase activities were measured as indices of oxidative stress. HIF- $1 \alpha$ content and key oxidative and glycolytic enzyme activities were determined. Contractile properties of sternohyoid muscle were determined ex vivo in the absence and presence of apocynin (putative NOX inhibitor). We observed an increase in NOX 2 and p47 phox expression in $\mathrm{ClH}$-exposed sternohyoid muscle with decreased aconitase and glutathione reductase activities. There was no evidence, however, of increased lipid peroxidation or protein oxidation in $\mathrm{ClH}$-exposed muscle. $\mathrm{ClH}$ exposure did not affect sternohyoid HIF-1 $\alpha$ content or aldolase, lactate dehydrogenase, or glyceraldehyde-3-phosphate dehydrogenase activities. Citrate synthase activity was also unaffected by $\mathrm{CIH}$ exposure. Apocynin significantly increased sternohyoid force and power. We conclude that $\mathrm{CIH}$ exposure upregulates NOX expression in rat sternohyoid muscle with concomitant modest oxidative stress but it does not result in a HIF-1 $\alpha$-dependent increase in glycolytic enzyme activity. Constitutive NOX activity decreases sternohyoid force and power. Our results implicate NOX-dependent reactive oxygen species in $\mathrm{ClH}$-induced upper airway muscle dysfunction which likely relates to redox modulation of key regulatory proteins in excitation-contraction coupling.

Keywords: apocynin, intermittent hypoxia, NADPH oxidase, oxidative stress, respiratory muscle, sternohyoid, sleep apnea, upper airway

\section{INTRODUCTION}

Obstructive sleep apnea syndrome (OSAS) is a debilitating oxidative stress disorder (Lavie, 2003) which is very common. OSAS is associated with a wide spectrum of co-morbidities including cardiovascular, metabolic and neurocognitive dysfunction (Verstraeten, 2007; Lévy et al., 2009). Chronic intermittent hypoxia $(\mathrm{CIH})$ is a central dominant feature of OSAS, and there is now convincing evidence from animal models that $\mathrm{CIH}$ recapitulates many of the hallmark features of the disorder. Upper airway (UA) muscle dysfunction is implicated in the pathophysiology of OSAS. OSAS patients (Carrera et al., 1999) and the English bulldog (Petrof et al., 1994), an animal model of OSAS, show signs of UA dilator muscle remodeling, dysfunction and damage. $\mathrm{CIH}$ alters UA muscle function (McGuire et al., 2002; Liu et al., 2005;
Pae et al., 2005; Dunleavy et al., 2008; Ding and Liu, 2011; Skelly et al., 2012a) and induces UA muscle structural remodeling in some (McGuire et al., 2002; Pae et al., 2005) but not all (Ray et al., 2007; Skelly et al., 2012a) studies.

$\mathrm{CIH}$ exposure is typically associated with an increased production of reactive oxygen species (ROS) (Prabhakar, 2001; Peng and Prabhakar, 2003; Yuan et al., 2004; Shan et al., 2007; Dunleavy et al., 2008; Dutta et al., 2008; Raghuraman et al., 2009; Sharma et al., 2009; Khan et al., 2011) which can contribute to the development of skeletal muscle dysfunction (Dunleavy et al., 2008; Dutta et al., 2008; Jackson, 2008; Ding and Liu, 2011; Skelly et al., 2012a; Shortt et al., 2014). Pro-oxidants exacerbate (Dunleavy et al., 2008), while antioxidant strategies ameliorate (Dunleavy et al., 2008; Skelly et al., 
2012a; Shortt et al., 2014) CIH-induced respiratory muscle dysfunction. Moreover, superoxide scavengers increase sternohyoid muscle force (Skelly et al., 2010, 2012b) highlighting that basal ROS production is inhibitory to UA muscle function. These observations highlight that ROS are important modulators of respiratory muscle performance under physiological and pathophysiological conditions. Although it is well established that $\mathrm{CIH}$ increases ROS production, the source of ROS is less clear. $\mathrm{CIH}$-induced oxidative stress in the liver (Jun et al., 2008), cardiovascular system (Nisbet et al., 2009), and brain (Hui-guo et al., 2010) is ameliorated by the inhibition of NADPH oxidase (NOX) activity suggesting that this membrane-bound superoxide generating enzyme is a major source of CIH-induced ROS. In skeletal muscle fibers, NOXs are localized to the sarcoplasmic reticulum (Xia et al., 2003), transverse tubules (Hidalgo et al., 2006), and plasma membranes (Javesghani et al., 2002); inhibition of NOXs in skeletal muscle reduces the levels of superoxide (Javesghani et al., 2002; Patwell et al., 2004). We recently reported that $\mathrm{CIH}$-induced diaphragm dysfunction in the rat is blocked by chronic supplementation with the putative NOX inhibitor-apocynin (Shortt et al., 2014). Together, these studies implicate a role for NOX-derived ROS in skeletal muscle (dys) function.

We sought to determine the effects of $\mathrm{CIH}$ on the expression levels of NOX proteins in rat sternohyoid muscle (a representative UA dilator critical in the control of airway caliber) and to establish whether or not $\mathrm{CIH}$ alters the redox status of the sternohyoid. In functional studies of sternohyoid muscle ex vivo, we explored the effects of apocynin on isometric and isotonic contractile properties. We postulated that $\mathrm{CIH}$ upregulates NOX expression in rat sternohyoid muscle resulting in oxidative stress and that NOXdependent ROS exert an inhibitory effect on sternohyoid forceand power-generating capacity.

\section{MATERIALS AND METHODS ETHICAL APPROVAL}

All procedures involving animals were performed under license from the Irish Government Department of Health and Children and were carried out in accordance with National and European guidelines, following approval from University College Dublin Animal Research Ethics Committee.

\section{CHRONIC INTERMITTENT HYPOXIA}

Adult male Wistar rats were exposed to sham or chronic intermittent hypoxia $(\mathrm{CIH})$ exposure. Rats were housed as normal in standard cages placed within commercially designed environmental chambers (Oxycyler ${ }^{\mathrm{TM}}$, Biospherix, USA) for daily gas treatments. Ambient oxygen was servo-controlled to generate intermittent hypoxia: $90 \mathrm{~s}$ hypoxia $\left(5 \% \mathrm{O}_{2}\right.$ at the nadir) and $210 \mathrm{~s}$ normoxia $\left(21 \% \mathrm{O}_{2}\right), 12$ cycles per hour, $8 \mathrm{~h}$ per day for 14 consecutive days. A rodent pulse oximeter (Mouse $\mathrm{Ox}^{\mathrm{TM}}$ Starr Life Sciences Corp., USA) was used to determine the resulting arterial oxygen saturation $\left(\mathrm{SaO}_{2}\right)$ during $\mathrm{CIH}$ exposure; $\mathrm{SaO}_{2}$ decreased to $\sim 70-80 \%$ at the nadir of the recurrent hypoxic events. On the day following gas treatments, animals were euthanized humanely (cervical spinal transection under 5\% isoflurane anesthesia) and the sternohyoid muscles were excised.

\section{TISSUE PREPARATION}

Muscles were homogenized (GLH Homogeniser Omni International) in RIPA lysis buffer $(25 \mathrm{mM}$ Tris- $\mathrm{HCl} \mathrm{pH}$ $7.6,150 \mathrm{mM}$ sodium chloride, $1 \% \mathrm{NP}-40,1 \%$ sodium deoxycholate, $0.1 \%$ SDS) supplemented with protease inhibitor cocktail ( $1 \mathrm{mM}$ AEBSF, $800 \mu \mathrm{M}$ aprotinin, $40 \mu \mathrm{M}$ bestatin, $14 \mu \mathrm{M} \mathrm{E}-64$, $20 \mu \mathrm{M}$ leupeptin, $15 \mu \mathrm{M}$ pepstatin A; Sigma Aldrich, Ireland) and phosphatase inhibitors $10 \mathrm{mM}$ sodium fluoride, $1 \mathrm{mM}$ sodium orthovanadate, using a $10 \% \mathrm{w} / \mathrm{v}$ ratio. Samples were homogenized using $8 \times 10 \mathrm{~s}$ bursts and left on ice for $20 \mathrm{~min}$. Homogenates were then centrifuged for $15 \mathrm{~min}$ at $11,000 \mathrm{~g}$ and the supernatants were stored at $-80^{\circ} \mathrm{C}$. Protein concentration was determined using a bicinchoninic (BCA) assay (Thermo Scientific, Ireland) as described in the manufacturer's protocol with absorbances measured at $562 \mathrm{~nm}$ using a SpectraMax-M3 spectrophotometer (Molecular Devices, USA).

\section{WESTERN BLOTTING}

Protein samples were mixed with an equal volume of $2 \mathrm{x}$ laemmli buffer ( $4 \%$ sodium dodecyl sulfate (SDS), $10 \%$ $\beta$-mercaptoethanol, 20\% glycerol, $0.004 \%$ bromophenol blue, $0.125 \mathrm{M}$ Tris- $\mathrm{HCl}, \mathrm{pH} 6.8$ ) and $15 \mu \mathrm{g}$ of protein from each sample was resolved on 7.5 and $12.5 \%$ SDS-polyacrylamide gels depending on the protein. Resolved proteins were then electrophoretically transferred onto nitrocellulose membranes (BioRad, Hercules, CA). Membranes were incubated in $0.1 \%(\mathrm{w} / \mathrm{v})$ Ponceau $S$ in $5 \%$ acetic acid to reversibly stain the transferred proteins to assess equal protein loading and transfer, and were digitally photographed for densitometric analysis. The membranes were blocked for $1 \mathrm{~h}$ in TBST (20 mM Tris-HCl, pH 7.6, $150 \mathrm{mM} \mathrm{NaCl}, 0.1 \%$ Tween) containing 5\% non-fat dried milk and were incubated overnight with the primary antibody specific for the protein of interest as follows: anti-NOX 2 and anti-p47 phox, 1:1000 (BD Biosciences, UK); anti-p22 phox, 1:1000 (Santa Cruz, USA); anti-4-HNE, 1:2000 (Millipore, Ireland).

Membranes were incubated for $1 \mathrm{~h}$ at room temperature with a 1:2000 dilution of HRP-linked anti-rabbit or anti-mouse secondary antibody (Cell Signaling Technology, USA) in 5\% non-fat dried milk/TBST depending on the primary antibody of interest. Bands were visualized using enhanced chemiluminescence (ECL Plus, GE Healthcare, UK) and exposure to chemiluminescent sensitive film (Kodak, USA). Films were developed, digitally photographed and densitometric analysis of bands of interest was performed (QuantityOne, Biorad). Band intensities of proteins of interest were normalized to the intensities of the corresponding Ponceau $\mathrm{S}$ staining proteins which were also measured by densitometric analysis to adjust for protein loading, allowing comparative analysis between sham and $\mathrm{CIH}$-exposed muscles.

\section{PROTEIN FREE THIOL AND CARBONYL GROUP CONTENT}

Muscle homogenates were incubated with either $2 \mathrm{mM}$ iodoacetamidofluorescein (IAF) or $2 \mathrm{mM}$ fluorescein-thiosemicarbazide (FTSC) (Sigma-Aldrich Co., Ireland) for $2 \mathrm{~h}$ in the dark on ice for detection of protein free thiol and carbonyl groups, respectively. Samples were then precipitated with $20 \%$ trichloroacetic acid (TCA) in acetone, followed by centrifugation at 11,000 $\mathrm{g}$ at $4^{\circ} \mathrm{C}$ for $3 \mathrm{~min}$. Protein pellets were then washed with ice-cold 
excess 1:1 ethylacetate/ethanol or acetone (for FTSC and IAF respectively) to remove excess TCA, interfering salts and nonprotein contaminants. Samples were dried, re-suspended in sample buffer containing $5 \% \beta$-mercaptoethanol and heated at $95^{\circ} \mathrm{C}$ for $5 \mathrm{~min}$ before $1 \mathrm{D}$ electrophoretic separation on a $12 \%$ polyacrylamide gel. Fluorescent images of the gels were captured on a Typhoon Trio+ Variable-Mode Imager (GE Healthcare, UK). Protein bands were visualized by colloidal coomassie staining and images were captured on a calibrating image densitometer (GS-800, Bio-Rad, USA).

\section{HIF-1 $\alpha$ AND METABOLIC ENZYME ACTIVITIES}

Sternohyoid HIF- $1 \alpha$ content was assayed by an immuno-linked luminescence assay in accordance with manufacturer's instructions (Mesoscale Discovery, Gaithersburg, USA). HeLa cells treated with and without cobalt chloride for $16 \mathrm{~h}$ provided positive and negative controls respectively for the HIF- $1 \alpha$ assay. Aconitase activity was measured using a colorimetric reaction in accordance with the manufacturer's instructions (Abcam, Cambridge, UK). Aconitase is a TCA cycle enzyme that catalyzes the isomerisation of citrate to isocitrate. Isocitrate, in this assay, undergoes further biochemical reaction resulting in a product that converts a nearly colorless probe into an intensely colored form with a peak absorbance at $450 \mathrm{~nm}$. Samples were incubated in an activating solution containing cysteine- $\mathrm{HCl}$ and $\left(\mathrm{NH}_{4}\right)_{2} \mathrm{Fe}\left(\mathrm{SO}_{4}\right)_{2}$ on ice for $1 \mathrm{~h}$ before addition to a 96well plate in duplicate along with isocitrate standards. One half of the duplicate wells received the sample reaction mixture (containing assay buffer, enzyme mix and substrate) and the other half the background mixture (containing assay buffer and enzyme mix only) and samples were incubated for $60 \mathrm{~min}$ at $25^{\circ} \mathrm{C}$. Developer was then added to each well and samples were incubated for a further $10 \mathrm{~min}$. Absorbance was measured at $450 \mathrm{~nm}$ and background was subtracted from the test sample. One unit of aconitase activity is the amount of enzyme that will isomerize 1 mmoles of isocitrate per minute at $\mathrm{pH}$ 7.4 and $25^{\circ} \mathrm{C}$. Fructose-1, 6-bisphosphate Aldolase A (aldolase) is the isoform of the enzyme found predominantly in skeletal muscle. It is the 4 th enzyme of the glycolysis pathway which catalyzes the conversion of fructose-1-6-bisphosphate into both 3-phosphoglyceraldehyde and dihydroxyacetone phosphate. We developed an assay based upon Boyer's modification of the hydrazine assay where 3-phosphoglyceraldehyde reacts with hydrazine to form a hydrazone which absorbs at $240 \mathrm{~nm} .4 \mathrm{mM}$ fructose-1,6-bisphosphate ( $\mathrm{pH} 7.5)(25 \% \mathrm{v} / \mathrm{v}), 0.03 \mathrm{mM}$ EDTA $\mathrm{pH} 7.5(25 \% \mathrm{v} / \mathrm{v})$, and $2.3 \mathrm{mM}$ hydrazine sulfate $(25 \% \mathrm{v} / \mathrm{v})$ were added to a 96-well plate and absorbance was recorded for $10 \mathrm{~min}$. Samples and a $\mathrm{dH}_{2} \mathrm{O}$ blank $(25 \% \mathrm{v} / \mathrm{v})$ were then added to the plate and absorbance was recorded for another $10 \mathrm{~min}$. Using the linear portions of the curve, the $\mathrm{A}_{240} / \mathrm{min}$ of the blank was subtracted from the $A_{240} / \mathrm{min}$ of the test. One unit is described as a change in absorbance of 1.00 per minute at $25^{\circ} \mathrm{C}$ and $\mathrm{pH}$ 7.5. For GAPDH activity measurement, samples were added to $13.5 \mathrm{mM}$ sodium pyrophosphate buffer ( $\mathrm{pH} 8.5$ ) containing $30 \mathrm{mM}$ sodium arsenate, $0.25 \mathrm{mM}$ NAD with $3.325 \mathrm{mM}$ DTT. Samples were incubated at $25^{\circ} \mathrm{C}$ for $10 \mathrm{~min}$ to achieve temperature equilibration and to establish a blank rate, if any. $0.5 \mathrm{mM}$ DL-glyceraldehdye-3-phosphate was added and absorbance was recorded for $10 \mathrm{~min}$ at $339 \mathrm{~nm}$. Measured rates were corrected by measuring the blank rate of the reaction. One unit is defined as $1 \mu \mathrm{mol} \mathrm{NADH}$ generated per minute. Citrate synthase activity was determined using a commercial kit (Sigma) as per manufacturer's instructions. Citrate synthase catalyzes the reaction between acetyl coenzyme A (acetyl CoA) and oxaloacetic acid (OAA) to form citric acid and CoA with a thiol group which reacts with DTNB in the reaction mixture to form 5-thio-nitrobemzoic acid (TNB) which is absorbed at $412 \mathrm{~nm}$. One unit causes the synthesis of one micromole of citrate per minute permg protein at $25^{\circ} \mathrm{C}$ and $\mathrm{pH} 7.5$.

\section{MUSCLE PHYSIOLOGY}

Adult male Wistar rats were anesthetized with 5\% isoflurane by inhalation in oxygen and killed by cervical spinal transection. Sternohyoid muscles were excised and longitudinal bundles were suspended vertically with fine (non-elastic) string; one end of each strip was mounted to tissue holders, while the other end was tied firmly to a hook, which sat on a dual-mode force transducer allowing assessment of isometric and isotonic properties. The muscle fiber bundles affixed to the tissue holders were then suspended in standard water-jacketed tissue baths. The tissue baths were filled with Krebs salt solution, maintained at $35^{\circ} \mathrm{C}$ and bubbled with $95 \% \mathrm{O}_{2}$ and $5 \% \mathrm{CO}_{2}$. The Krebs solution contained: $120 \mathrm{mM} \mathrm{NaCl}, 25 \mathrm{mM} \mathrm{NaHCO}, 12 \mathrm{mM}$ $\mathrm{MgSO}_{4}, 1.2 \mathrm{mM} \mathrm{NaH}{ }_{2} \mathrm{PO} 4,2.5 \mathrm{mM}$ CaGluconate, $5 \mathrm{mM} \mathrm{KCl}$, and $11.5 \mathrm{mM}$ Glucose. D-tubocurarine $(25 \mu \mathrm{M})$ was used in all experiments to exclude any potential involvement of excitation of intramuscular nerve branches. The muscles were stimulated using supramaximal square wave constant current stimulators delivered via two platinum electrodes which flanked the tissue in the bath. The change in tension was transduced, amplified and converted from an analog-to-digital signal where it was displayed and recorded on a computer for later analysis. Optimum muscle length $\left(\mathrm{L}_{\mathrm{o}}\right)$ was determined by repeated twitch stimulation while adjusting the length of the muscle with the micropositioner. The muscle preparations remained at $\mathrm{L}_{\mathrm{o}}$ for the duration of the study. Studies were conducted in the absence and presence of the putative NOX inhibitor, apocynin $(2 \mathrm{mM})$. Muscle preparations were allowed to equilibrate for $10 \mathrm{~min}$ before starting the experimental protocol.

\section{Protocol}

Isometric twitch force and kinetics (contraction time and halfrelaxation time) were determined with the lever arm of the force transducer set to maximum rigidity ( $~ 500 \mathrm{mN} ;>100 \%$ load). Next, an isometric tetanic contraction (Fmax) was elicited by stimulating at $100 \mathrm{~Hz}$ for $300 \mathrm{~ms}$ (O'Halloran, 2006; Skelly et al., 2010, 2012a,b; Shortt et al., 2014). Following a 5 min rest period, concentric contractions were elicited in incremental steps with varying load $(0.1,1,5,10,15,20 \%$; \% of Fmax) with 1 min rest between each contraction. Muscle length returned to $\mathrm{L}_{\mathrm{o}}$ following each contraction. Shortening (Smax) was determined as the maximum distance shortened during contraction. Peak shortening velocity (Vmax) was determined as distance shortened during the 
initial $30 \mathrm{~ms}$ of shortening, when velocity is greatest at $0 \%$ load. Mechanical power was determined at each step of the incremental load step test as the product of force $\mathrm{x}$ shortening velocity.

\section{DATA ANALYSIS}

Peak specific force (Fmax) was calculated in $\mathrm{N} / \mathrm{cm}^{2}$ of muscle cross-sectional area. Cross-sectional area was calculated as follows: mass $(\mathrm{g}) /\left(\mathrm{Lo}(\mathrm{cm}) \times\right.$ muscle density $\left(\mathrm{g} / \mathrm{cm}^{3}\right)$; muscle density was estimated to be $1.056 \mathrm{~g} / \mathrm{cm}^{3}$. Maximum shortening (Smax) was calculated as length shortened per optimal length $\left(\mathrm{L} / \mathrm{L}_{\mathrm{o}}\right)$. Peak shortening velocity $\left(\mathrm{V} \max\right.$ ) was calculated as $\mathrm{L}_{\mathrm{o}} / \mathrm{s}$. Peak mechanical power (Pmax) was calculated as Watts $/ \mathrm{cm}^{2}$.

\section{STATISTICAL ANALYSIS}

Data are expressed as mean \pm SEM. Statistical comparisons were performed between groups using Student unpaired $t$-tests, Mann Whitney $U$-tests, or Two-Way ANOVA with Bonferroni post-hoc tests as appropriate using Graph Pad Prism. $P<0.05$ was the criterion for statistical significance in all tests.

\section{RESULTS}

\section{EFFECT OF CIH ON STERNOHYOID NOX SUBUNIT AND MYOSIN EXPRESSION}

We postulated that $\mathrm{CIH}$ would increase sternohyoid NOX subunit expression. Western blots are shown in Figures 1A,B. CIH significantly increased NOX 2 (Figures 1A,C) and p47 phox
(Figures 1B,E)—but not p22 phox (Figures 1A,D)—expression in rat sternohyoid muscle. Total myosin protein content was unaffected by CIH exposure (not shown).

\section{EFFECT OF CIH ON STERNOHYOID 4-HNE PROTEIN ADDUCT LEVELS AND PROTEIN FREE THIOL AND CARBONYL GROUP CONTENT}

We postulated that $\mathrm{CIH}$ would increase lipid peroxidation and protein oxidation. Western blot with respective Ponceau $S$ stained gel is shown in Figure 2A. CIH exposure did not affect sternohyoid 4-HNE protein adduct levels (Figure 2B). Representative fluorescent 1D gels tagging protein free thiols (Figure 2C) and protein carbonyls (Figure 2E) are shown with respective coomassie stained gels. CIH exposure did not affect protein free thiol (Figure 2D) or carbonyl group (Figure 2F) content.

\section{EFFECT OF CIH ON STERNOHYOID MUSCLE ACONITASE AND GLUTATHIONE REDUCTASE ACTIVITIES}

We postulated that $\mathrm{CIH}$ would decrease aconitase and glutathione reductase activities indicative of oxidative stress. $\mathrm{CIH}$ exposure significantly decreased aconitase (Figure 3A) and glutathione reductase (Figure 3B) activities.

\section{EFFECT OF CIH ON STERNOHYOID MUSCLE HIF-1 $\alpha$ CONTENT AND OXIDATIVE AND GLYCOLYTIC ENZYME ACTIVITIES}

We postulated that $\mathrm{CIH}$ would increase HIF-1 $\alpha$ content and cause a shift from oxidative-to-glycolytic metabolism. CIH exposure

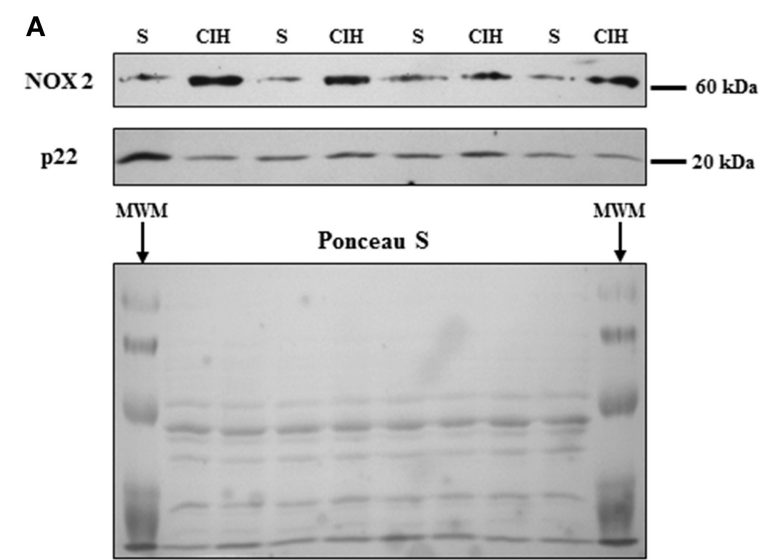

\section{B}

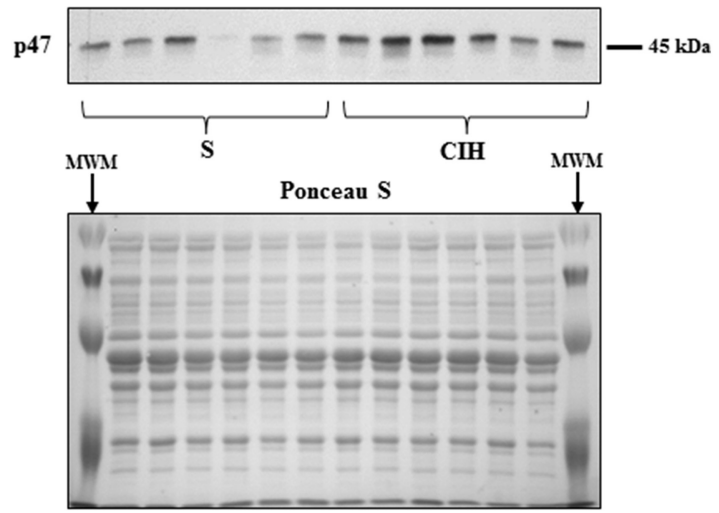

C

C $\quad \operatorname{sox} 2$

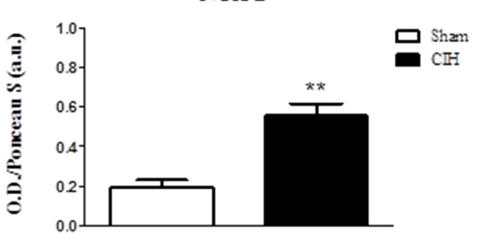

D

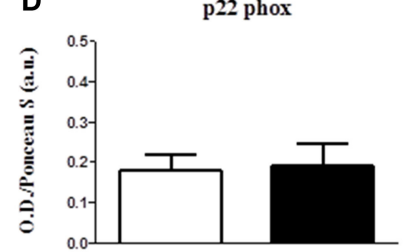

E

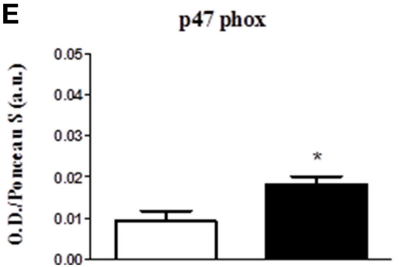

FIGURE 1 | Western blot of NOX subunit expression in the sternohyoid muscle from sham (S) and chronic intermittent hypoxia (ClH)-exposed rats. (A) Expression of the catalytic superoxide-generating NOX 2 subunit and the co-anchoring p22 phox subunit with the corresponding Ponceau S stained membrane used to normalize protein loading and electro-transfer. MWM = pre-stained molecular weight markers. (B) Expression of the organizer subunit, p47 phox with corresponding Ponceau S stained membrane. Densitometric analysis of NOX subunit band intensities normalized by densitometric intensities of corresponding Ponceau-S stained proteins expressed in arbitrary units (a.u.) are shown in (C-E). (C) A near 3-fold increase in NOX 2 expression was observed in the $\mathrm{ClH}$-exposed group compared to sham control $\left({ }^{* *} P=0.002\right.$; Student unpaired $t$-test, $n=4$ per group). (D) No change in the p22 phox subunit expression was observed ( $P=0.884, n=4$ per group). (E) A near 2 -fold increase in the $\mathrm{p} 47$ phox subunit expression was observed in the $\mathrm{ClH}$-exposed group compared to sham control ( $* P=0.014, n=6$ per group). Values are mean $\pm \mathrm{SEM}$. 


\section{A}

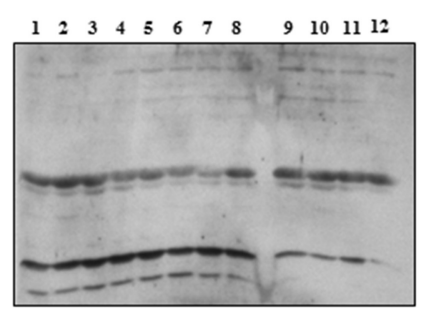

C Free Thiol Groups (IAF)

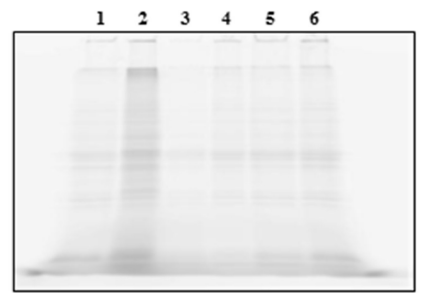

E Carbonyl Groups (FTSC)

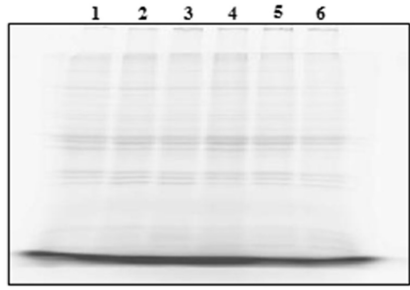

Ponceau $\mathrm{S}$

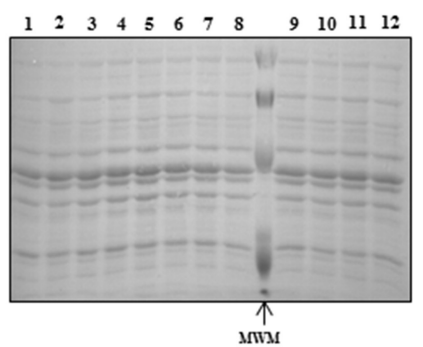

Coomassie

$\begin{array}{llllll}1 & 2 & 3 & 4 & 5 & 6\end{array}$
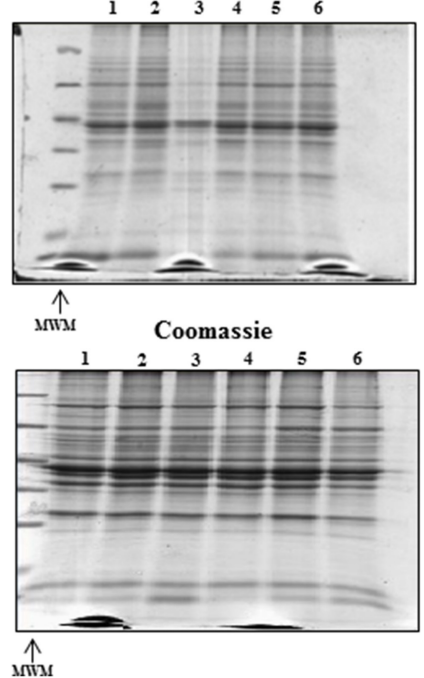

B

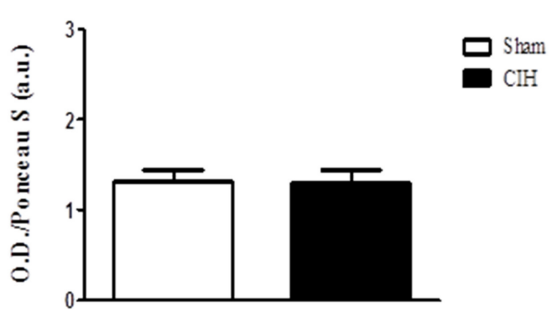

D

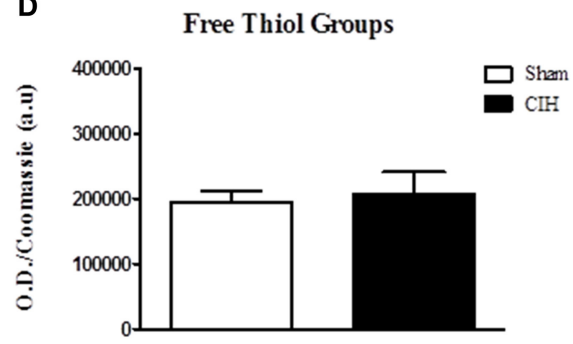

$\mathbf{F}$

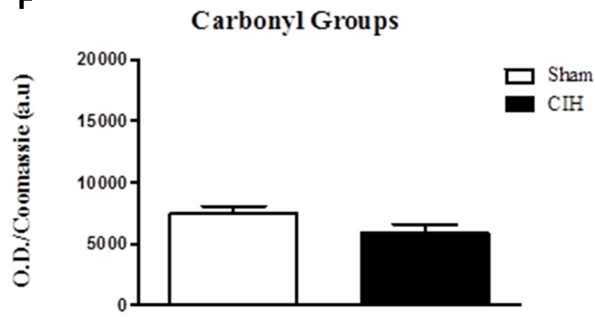

FIGURE 2 | Western blot of 4-HNE protein adducts and 1D electrophoresis to determine free thiol and carbonyl group content in the sternohyoid muscle from sham and chronic intermittent hypoxia (CIH)-exposed rats. Sham and $\mathrm{ClH}$ samples were loaded in alternate lanes (numbered in the figure). (A) Sternohyoid 4-HNE content together with Ponceau S stained membrane. (B) Densitometric analysis of 4-HNE protein adduct band intensities normalized by densitometric intensities of corresponding Ponceau S stained proteins expressed in arbitrary units (a.u.) from sham and $\mathrm{ClH}$-exposed rats. No significant difference was observed in 4-HNE protein adduct content ( $P=0.9372$; Student unpaired $t$-test) comparing sham and $\mathrm{ClH}$-exposed sternohyoid muscles. Representative images of sternohyoid iodoacetamidofluorescein (IAF)-tagged protein free thiol groups (C) and fluorescein-thiosemicarbazide (FTSC)-tagged carbonyl groups (E) with corresponding coomassie stained membranes used to normalize protein loading and electrotransfer. Densitometric analysis of protein free thiol group (D) and carbonyl group (F) contents normalized by densitometric intensities of corresponding coomassie stained proteins expressed in arbitrary units (a.u.) from sham and $\mathrm{ClH}$-exposed rats. Protein free thiol and carbonyl group content of the sternohyoid muscle was not significantly different in sham and $\mathrm{ClH}$-exposed rats $(P=0.699$ and $P=0.180$ respectively; Student unpaired $t$-tests). Values are mean \pm SEM; $n=6$ per group. did not affect sternohyoid HIF- $1 \alpha$ content (not shown). Similarly, $\mathrm{CIH}$ exposure did not affect citrate synthase $(0.23 \pm 0.01$ vs. $0.22 \pm 0.01$, mean \pm SEM, units/mg protein; Student unpaired $t$-test: $p=0.518)$, aldolase $(1.90 \pm 0.06$ vs. $2.00 \pm 0.11$ units $/ \mathrm{mg}$ protein; $p=0.425)$, lactate dehydrogenase ( $0.45 \pm 0.08$ vs. $0.42 \pm$ 0.08 units/mg protein; $p=0.805$ ) or glyceraldehyde-3-phosphate dehydrogenase $(0.56 \pm 0.12$ vs. $0.53 \pm 0.09$ units/mg protein; $p=0.845)$ activities.

\section{EFFECT OF APOCYNIN ON STERNOHYOID MUSCLE CONTRACTILE PROPERTIES}

We postulated that the putative NOX inhibitor-apocyninwould increase force- and power-generating capacity of the sternohyoid muscle. Data for sternohyoid muscle contractile properties are shown in Table 1. Contractile kinetics and twitch force determined during isometric contractions were unaffected by apocynin. There was an increase in the maximum velocity of shortening (Vmax) in apocynin-treated preparations during isotonic contractions but this did not achieve statistical significance $(p=0.095)$. Maximum muscle shortening during isometric contractions (Smax) was unaffected by apocynin. Conversely, apocynin significantly increased sternohyoid muscle peak tetanic force (Fmax; Figure 4A) determined under isometric conditions and increased muscle power (force $\mathrm{x}$ velocity of shortening; Figure 4B) over a range of loads (10-20\% of Fmax) during concentric contractions.

\section{DISCUSSION}

The key findings of this study are: (1) CIH significantly increased NOX 2 and p47 phox-but not p22 phox-subunit expression in rat sternohyoid muscle; (2) $\mathrm{CIH}$ did not increase the levels of sternohyoid 4-HNE protein adducts; (3) $\mathrm{CIH}$ did not 


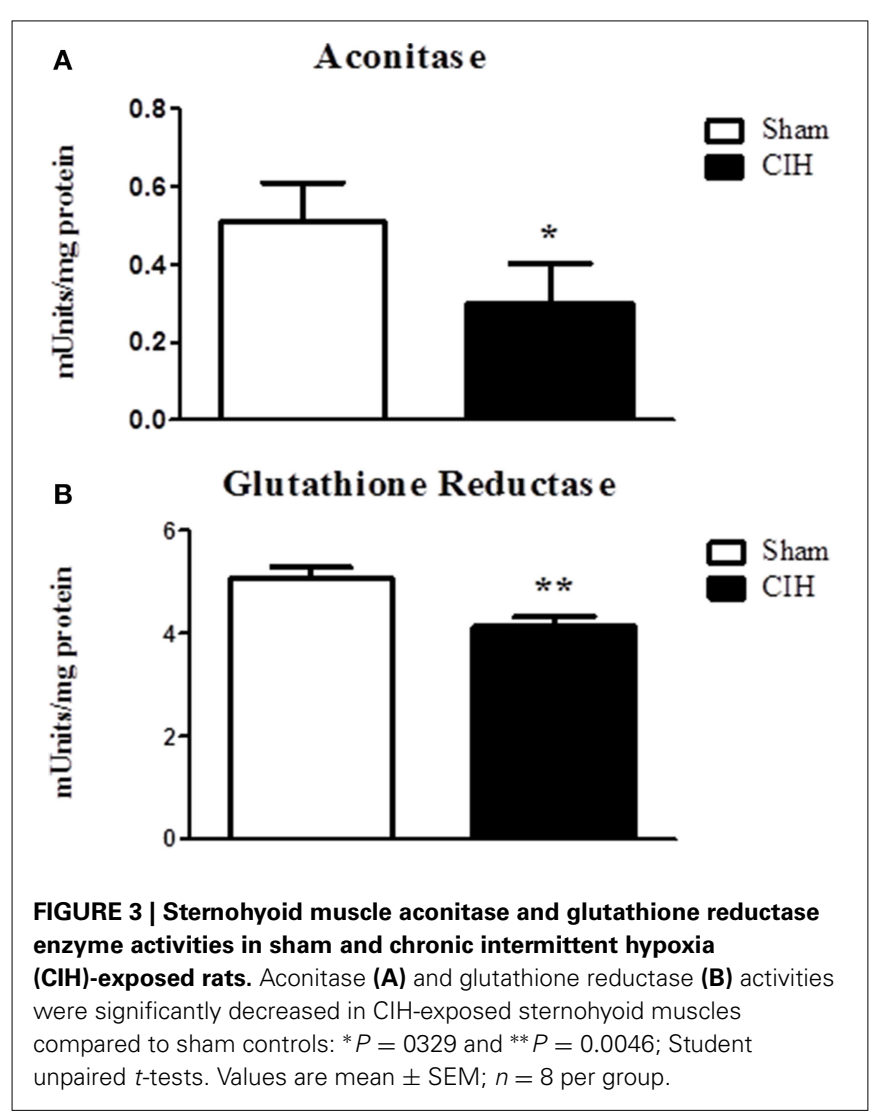

Table 1 | Sternohyoid muscle contractile properties in the absence and presence of $2 \mathrm{mM}$ apocynin.

\begin{tabular}{lccc}
\hline & Control & Apocynin & $P$-value \\
\hline $\mathrm{CT}(\mathrm{ms})$ & $15 \pm 1$ & $17 \pm 2$ & $0.407^{\mathrm{a}}$ \\
$1 / 2 \mathrm{RT}(\mathrm{ms})$ & $12 \pm 1$ & $12 \pm 2$ & $0.647^{\mathrm{a}}$ \\
$\mathrm{Pt}\left(\mathrm{N} / \mathrm{cm}^{2}\right)$ & $2.5 \pm 0.6$ & $2.6 \pm 0.2$ & $0.922^{\mathrm{b}}$ \\
$\mathrm{V} \max (\mathrm{Lo} / \mathrm{s})$ & $6.5 \pm 0.8$ & $8.9 \pm 0.7$ & $0.095^{\mathrm{c}}$ \\
$\mathrm{S} \max (\mathrm{L} / \mathrm{Lo})$ & $0.29 \pm 0.02$ & $0.34 \pm 0.03$ & $0.129^{\mathrm{a}}$ \\
\hline
\end{tabular}

Values are mean $\pm S E M ; n=5$ for both groups. $C T$, isometric contraction time; $1 / 2 R T$, isometric half-relaxation time; $P$ t, isometric twitch force; Vmax, maximum shortening velocity under isotonic conditions of zero load normalized to optimum length (Lo); Smax, peak shortening normalized to Lo. Data were compared using a Student unpaired t-test, ${ }^{b}$ Student unpaired t-test with Welch's correction or ${ }^{c}$ Mann Whitney U-test as appropriate following tests for normality and equal variances in the data sets.

affect protein free thiol or carbonyl group content in sternohyoid muscle; (4) $\mathrm{CIH}$ decreased aconitase and glutathione reductase activities indicative of modest oxidative stress; (5) CIH did not affect HIF- $1 \alpha$ content or the activities of citrate synthase, aldolase, lactate dehydrogenase or glyceraldehyde-3-phosphate dehydrogenase; (6) The putative NOX inhibitor-apocynin—significantly increased sternohyoid force and power.

It is well established in various animal models that $\mathrm{CIH}$ impairs respiratory muscle function (Dunleavy et al., 2008; Skelly et al., 2010, 2012a; Shortt et al., 2014). We have previously

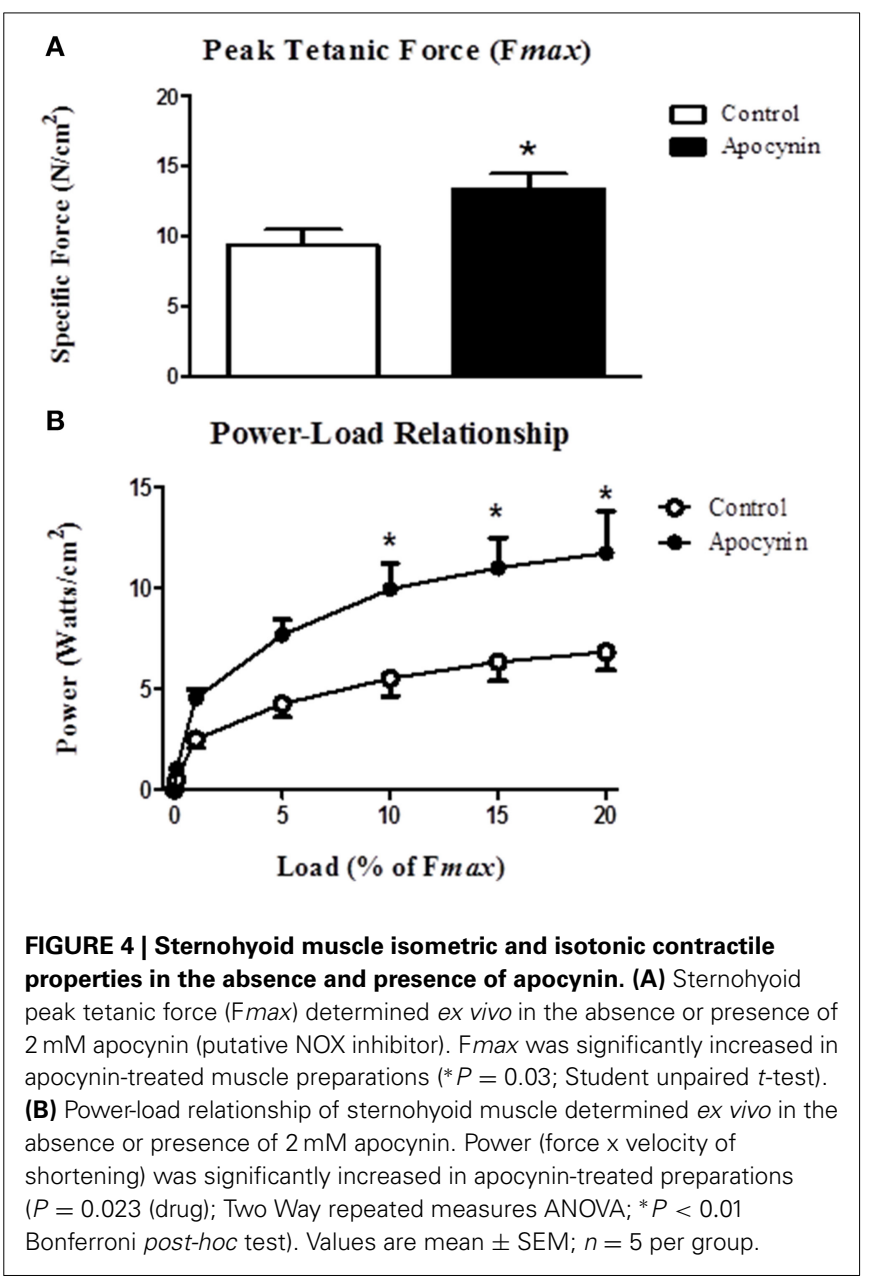

reported sternohyoid muscle weakness in adult male Wistar rats, an effect that was ameliorated by chronic tempol (a superoxide scavenger) supplementation (Skelly et al., 2012a) implicating ROS in CIH-induced muscle dysfunction. A variety of sources of ROS have been described but the major contributing source in $\mathrm{CIH}$-induced UA muscle dysfunction has yet to be determined. A number of models have identified the NOX complex as a potential source of ROS contributing to redox modulation and/or oxidative injury (Pigeolet et al., 1990; Berry et al., 2000; Ozaki et al., 2000; Javesghani et al., 2002; Hidalgo et al., 2006; Nair et al., 2011; Shortt et al., 2014). Xia et al. (2003) identified a much higher rate of superoxide production per milligram of protein in the sarcoplasmic reticulum compared to the mitochondria in muscle. In view of these studies and our previous work (Skelly et al., 2010, 2012a,b), we sought to investigate NOX as a potential source of ROS in CIH-exposed UA muscle.

The present study shows that $\mathrm{CIH}$ exposure increased key NOX subunits in sternohyoid muscle. We observed a near 3-fold increase in the catalytic subunit-NOX 2-and a near 2-fold increase in the organizer subunit $-\mathrm{p} 47$ phox. There is a body of research that implicates hypoxia as a driving force underpinning enhanced NOX expression and activity in various tissues. Acute repetitive hypoxia was shown to increase NOX activity $\sim 12$-fold in the carotid body (Peng et al., 2009). This increase in activity was 
associated with an increase in NOX mRNA and protein expression. CIH was also shown to increase NOX 2 protein and mRNA expression in PC12 pheochromocytoma cells as well as mouse embryonic fibroblasts mediated through hypoxia inducible factor 1 (HIF-1) (Yuan et al., 2011). Similarly, Souvannakitti et al. (2010) showed that CIH increases NOX 2 activity and mRNA expression in adrenal medullae of neonatal rats. Recent work by Zhou et al. (2012) examined the effects of different CIH paradigms, reporting time- and intensity-dependent increases in rat myocardial p22 phox mRNA expression. Extending this line of enquiry, ours is the first study to our knowledge to report an increase in NOX 2 and $\mathrm{p} 47$ phox protein subunits in $\mathrm{CIH}$-exposed UA respiratory muscle and this appears to be independent of HIF-1 $\alpha$ activation. We acknowledge, however, that the exact site(s) of NOX subunit upregulation is not known and it could extend to the muscle vasculature; this is a limitation of the experimental approach taken in the present study.

Animal models of CIH most often report evidence of increased oxidative stress in various tissues, consistent with the observation that human OSAS is an oxidative stress disorder (Lavie, 2003). Despite reporting a significant increase in NOX subunit expression in CIH-exposed sternohyoid muscle, we did not detect overt oxidative stress in the tissue, assessed by measurement of protein free thiol and carbonyl group content. This was further corroborated by assessment of the levels of 4-HNE (a highly reactive lipid peroxidation product and initiator of oxidative stress) which was unchanged in the $\mathrm{CIH}$-exposed airway dilator muscle. On the face of it, the apparent lack of oxidative stress following $\mathrm{CIH}$ is surprising given our previous findings that antioxidant supplementation ameliorates or prevents $\mathrm{CIH}$-induced respiratory muscle dysfunction (Dunleavy et al., 2008; Skelly et al., 2012a; Shortt et al., 2014). Of note however, CIH-induced sternohyoid muscle dysfunction is reversible by acute antioxidant treatment following CIH exposure (Skelly et al., 2012a). The latter observation strongly suggests that $\mathrm{CIH}$ exposure does not cause irreversible oxidative modification (damage) to muscle, consistent with the lack of evidence of increased protein carbonylation in $\mathrm{CIH}$-exposed muscle reported in the present study. Rather, $\mathrm{CIH}$-induced sternohyoid muscle weakness (Skelly et al., 2012a) appears to be a dynamic ROS-dependent process that is entirely reversible, which is important in the context of potential antioxidant pharmacotherapy for human OSAS. Of note, CIH was associated with significant decreases in aconitase and glutathione reductase activities highlighting the development of a modest oxidative stress in $\mathrm{CIH}$-exposed muscle.

In view of the collective data described above, we speculate that $\mathrm{CIH}$-induced sternohyoid dysfunction (Skelly et al., 2012a) is mediated by altered redox signaling, perhaps within microdomains of the muscle, evidently with no widespread cellular stress. A number of groups have reported localization of the NOX subunit complex, or at least some components, to areas near the sarcoplasmic reticulum and transverse tubules of muscle (Xia et al., 2003; Hidalgo et al., 2006; Sun et al., 2011). Oxidation of redox-sensitive cysteine residues in these microdomains affects calcium release through ryanodine receptor channels (Hidalgo et al., 2006; Sun et al., 2011); $\mathrm{Ca}^{2+}$ release is promoted during low level ROS turnover but is inhibited during high level ROS production (Geiszt et al., 1997; Kawakami and Okabe, 1998; Reid, 2001). Thus, it is plausible to suggest that CIH-induced NOXdependent elevated ROS might impair muscle force-generating capacity without concomitant widespread oxidative stress/injury. $\mathrm{CIH}$-induced oxidative damage has been observed in skeletal muscle (Dutta et al., 2008) and other tissues (Veasey et al., 2004; Raghuraman et al., 2009; Khan et al., 2011). It appears that the detrimental effects of CIH manifest in a "dose"-dependent manner and the effects of oxidative stress may be organ-specific (Shan et al., 2007; Jun et al., 2008). It is worth noting that the experimental paradigm of CIH used in our studies is relatively modest and based on the observations of Raghuraman et al. (2009), that short bouts of IH (15 s hypoxia; 5 min normoxia) produce higher levels of ROS compared to $90 \mathrm{~s}$ hypoxic/normoxic cycles, our paradigm might not be expected to produce severe oxidative stress per se.

To explore the potential for NOX-dependent ROS to modulate sternohyoid muscle performance, we examined the effects of apocynin on sternohyoid muscle contractile properties. Apocynin significantly increased isometric sternohyoid peak force revealing that basal NOX-derived ROS exert a powerful inhibitory influence on sternohyoid contractile performance. This finding is consistent with a previous study by our group highlighting that superoxide scavengers are powerful inotropic agents (Skelly et al., 2010, 2012a), extending this work to suggest that NOX is an important source of basal ROS production in rat sternohyoid muscle. Of note, apocynin did not affect isometric contractile kinetics although an increase in the maximum velocity of shortening under isotonic conditions was observed. This failed to achieve statistical significance but the increase likely contributed to the increase in power-generating capacity observed in apocynintreated preparations. The greater power-generating capacity of the sternohyoid over physiological loads (predominantly due to increased force-generating capacity) translates in vivo to a greater capacity to preserve and maintain UA caliber, given that the sternohyoid is a recognized UA dilator muscle. Our data highlight that ROS are powerful inhibitors of sternohyoid force and power, and by extension we posit that increased ROS associated with $\mathrm{CIH}$ (or other stimuli including enhanced muscle activity) impairs sternohyoid muscle function. The significance of our findings, in concert with our previous study (Skelly et al., 2012a), is that $\mathrm{CIH}$ exposure-a dominant feature of human sleep-disordered breathing - is detrimental to the control of UA caliber, potentially increasing the risk of obstructive airway events. In this regard, $\mathrm{CIH}$ exposure could establish an inescapable cycle serving to exacerbate and perpetuate respiratory morbidity in human OSAS.

It is plausible to suggest that NOX-derived ROS could affect contractile function through actions at one or more sites critical in the excitation-contraction coupling mechanism (Geiszt et al., 1997; Kawakami and Okabe, 1998; Reid, 2001; Hidalgo et al., 2006; van der Poel et al., 2007; Lamb and Westerblad, 2011; Sun et al., 2011). It is likely that ROS downstream of superoxide, such as hydrogen peroxide, affect sternohyoid muscle performance (Shortt and O'Halloran, 2014). We speculate that the inotropic effects of apocynin relate to redox modulation of calcium sensitivity of the contractile filaments (Edwards et al., 2007; Murphy et al., 2008). Collectively, the data are consistent with the 
widely held view that ROS are important signaling molecules in the context of skeletal muscle function. By extension, we postulate that increased NOX-derived ROS production following $\mathrm{CIH}$ exposure is likely responsible for sternohyoid muscle weakness (Skelly et al., 2012a), given that ROS are inhibitory to sternohyoid force (this study; Skelly et al., 2010, 2012a,b).

In summary, we have previously shown that $\mathrm{CIH}$ exposure causes upper airway dilator muscle weakness, an effect which is blocked by chronic antioxidant supplementation. Here we report that $\mathrm{CIH}$ exposure results in increased sternohyoid muscle NOX 2 and p47 phox subunit expression with attendant modest oxidative stress. Apocynin significantly enhanced sternohyoid muscle forceand power-generating capacity. Our results implicate NOX as a potential source of ROS which exert substantial inhibitory effects on sternohyoid muscle performance. We speculate that $\mathrm{CIH}$ induced muscle dysfunction relates to NOX-dependent redox modulation within specific myocellular microdomains relevant to contractile function. The results are further supportive of our previous contention that antioxidant treatment may serve as a useful adjunctive therapy in human OSAS.

\section{AUTHOR CONTRIBUTIONS}

Fiona B. McDonald and Eric Lucking generated the animal model; Robert Williams and Vincent Healy performed electrophoresis and densitometry; Paul Lemaire and Philip Lewis performed enzyme assays; Sean Hogan and Philip Lewis performed muscle physiology experiments; David Sheehan provided advice and expertise on 1D electrophoresis experiments which were performed in his laboratory; all authors contributed to interpretation of the data sets; Ken D. O'Halloran conceived the idea of the study and designed the experiments; Robert Williams drafted the original manuscript; critical revision was provided by David Sheehan, Vincent Healy and Ken D. O'Halloran; all authors approved the final version of the manuscript.

\section{ACKNOWLEDGMENTS}

Funded by the Health Research Board (Ireland) and the Department of Physiology, School of Medicine, University College Cork, Ireland.

\section{REFERENCES}

Berry, C., Hamilton, C. A., Brosnan, M. J., Magill, F. G., Berg, G. A., McMurray, J. J. V., et al. (2000). Investigation into the sources of superoxide in human blood vessels: angiotensin II increases superoxide production in human internal mammary arteries. Circulation 101, 2206-2212. doi: 10.1161/01.CIR.101.18.2206

Carrera, M., Barbe, F., Sauleda, J., Tomas, M., Gomez, C., and Agusti, A. G. (1999). Patients with obstructive sleep apnea exhibit genioglossus dysfunction that is normalized after treatment with continuous positive airway pressure. Am. J. Respir. Crit. Care Med. 159, 1960-1966. doi: 10.1164/ajrccm.159.6.9809052

Ding, W. H., and Liu, Y. H. (2011). Genistein attenuates genioglossus muscle fatigue under chronic intermittent hypoxia by down-regulation of oxidative stress level and up-regulation of antioxidant enzyme activity through ERK1/2 signaling pathway. Oral Dis. 17, 677-684. doi: 10.1111/j.1601-0825.2011.01822.x

Dunleavy, M., Bradford, A., and O'Halloran, K. D. (2008). Oxidative stress impairs upper airway muscle endurance in an animal model of sleep-disordered breathing. Adv. Exp. Med. Biol. 605, 458-462. doi: 10.1007/978-0-387-73693-8_80

Dutta, A., Ray, K., Singh, V. K., Vats, P., Singh, S. N., and Singh, S. B. (2008). L-carnitine supplementation attenuates intermittent hypoxia-induced oxidative stress and delays muscle fatigue in rats. Exp. Physiol. 93, 1139-1146. doi: 10.1113/expphysiol.2008.042465
Edwards, J. N., Macdonald, W. A., van der Poel, C., and Stephenson, D. G. (2007). $\mathrm{O} 2$ - production at 37 degrees $\mathrm{C}$ plays a critical role in depressing tetanic force of isolated rat and mouse skeletal muscle. Am. J. Physiol. Cell Physiol. 293, C650-C660. doi: 10.1152/ajpcell.00037.2007

Geiszt, M., Kapus, A., Német, K., Farkas, L., and Ligeti, E. (1997). Regulation of capacitative $\mathrm{Ca}^{2+}$ influx in human neutrophil granulocytes: alterations in chronic granulomatous disease. J. Biol. Chem. 272, 26471-26478. doi: 10.1074/jbc.272.42.26471

Hidalgo, C., Sánchez, G., Barrientos, G., and Aracena-Parks, P. (2006). A transverse tubule NADPH oxidase activity stimulates calcium release from isolated triads via ryanodine receptor type 1 S-glutathionylation. J. Biol. Chem. 281, 26473-26482. doi: 10.1074/jbc.M600451200

Hui-guo, L., Kui, L., Yan-ning, Z., and Yong-jian, X. (2010). Apocynin attenuate spatial learning deficits and oxidative responses to intermittent hypoxia. Sleep Med. 11, 205-212. doi: 10.1016/j.sleep.2009.05.015

Jackson, M. J. (2008). Free radicals generated by contracting muscle: by-products of metabolism or key regulators of muscle function? Free Rad. Biol. Med. 44, 132-141. doi: 10.1016/j.freeradbiomed.2007.06.003

Javesghani, D., Magder, S. A., Barreiro, E., Quinn, M. T., and Hussain, S. N. A. (2002). Molecular characterization of a superoxide-generating $\mathrm{NAD}(\mathrm{P}) \mathrm{H}$ oxidase in the ventilatory muscles. Am. J. Respir. Crit. Care Med. 165, 412-418. doi: 10.1164/ajrccm.165.3.2103028

Jun, J., Savransky, V., Nanayakkara, A., Bevans, S., Li, J., Smith, P. L., et al. (2008). Intermittent hypoxia has organ-specific effects on oxidative stress. Am. J. Physiol. Regul. Integr. Comp. Physiol. 295, R1274-R1281. doi: 10.1152/ajpregu.90346.2008

Kawakami, M., and Okabe, E. (1998). Superoxide anion radical-triggered $\mathrm{Ca}^{2+}$ release from cardiac sarcoplasmic reticulum through ryanodine receptor $\mathrm{Ca}^{2+}$ channel. Mol. Pharmacol. 53, 497-503.

Khan, S. A., Nanduri, J., Yuan, G., Kinsman, B., Kumar, G. K., Joseph, J., et al. (2011). NADPH oxidase 2 mediates intermittent hypoxia-induced mitochondrial complex I inhibition: relevance to blood pressure changes in rats. Antiox. Redox Signal. 14, 533-542. doi: 10.1089/ars.2010.3213

Lamb, G. D., and Westerblad, H. (2011). Acute effects of reactive oxygen and nitrogen species on the contractile function of skeletal muscle. J. Physiol. 589, 2119-2127. doi: 10.1113/jphysiol.2010.199059

Lavie, L. (2003). Obstructive sleep apnoea syndrome- an oxidative stress disorder. Sleep Med. Rev. 7, 35-51. doi: 10.1053/smrv.2002.0261

Lévy, P., Bonsignore, M. R., and Eckel, J. (2009). Sleep, sleep-disordered breathing and metabolic consequences. Eur. Respir. J. 34, 243-260. doi: 10.1183/09031936.00166808

Liu, S. S., Liu, H. G., Xiong, S. D., Niu, R. J., Xu, Y. J., and Zhang, Z. X. (2005). Effects of Shen-Mai injection on sternohyoid contractile properties in chronic intermittent hypoxia rat. Zhonghua Jie $\mathrm{He} \mathrm{He} \mathrm{Hu} \mathrm{Xi} \mathrm{Za} \mathrm{Zhi} \mathrm{28,}$ 611-614.

McGuire, M., MacDermott, M., and Bradford, A. (2002). Effects of chronic episodic hypoxia on rat upper airway muscle contractile properties and fiber-type distribution. Chest 122, 1012-1017. doi: 10.1378/chest.122.3.1012

Murphy, R. M., Dutka, T. L., and Lamb, G. D. (2008). Hydroxyl radical and glutathione interactions alter calcium sensitivity and maximum force of the contractile apparatus in rat skeletal mscle fibres. J. Physiol. 586, 2203-2216. doi: 10.1113/jphysiol.2007.150516

Nair, D., Dayyat, E. A., Zhang, S. X., Wang, Y., and Gozal, D. (2011). Intermittent hypoxia-induced cognitive deficits are mediated by NADPH oxidase activity in a murine model of sleep apnea. PLoS ONE 6:e19847. doi: 10.1371/journal.pone.0019847

Nisbet, R. E., Graves, A. S., Kleinhenz, D. J., Rupnow, H. L., Reed, A. L., Fan, T.-H. M., et al. (2009). The role of NADPH oxidase in chronic intermittent hypoxia-induced pulmonary hypertension in mice. Am. J. Respir. Cell Mol. Biol. 40, 601-609. doi: 10.1165/2008-0145OC

O'Halloran, K. D. (2006). Effects of nicotine on rat sternohyoid muscle contratile properties. Respir. Physiol. Neurobiol. 150, 200-210. doi: 10.1016/j.resp.2005.05.018

Ozaki, M., Deshpande, S. S., Angkeow, P., Bellan, J., Lowenstein, C. J., Dinauer, M. C., et al. (2000). Inhibition of the Racl GTPase protects against nonlethal ischemia/reperfusion-induced necrosis and apoptosis in vivo. FASEB J. $14,418-429$.

Pae, E.-K., Wu, J., Nguyen, D., Monti, R., and Harper, R. M. (2005). Geniohyoid muscle properties and myosin heavy chain composition are altered after 
short-term intermittent hypoxic exposure. J. Appl. Physiol. 98, 889-894. doi: 10.1152/japplphysiol.00978.2004

Patwell, D. M., McArdle, A., Morgan, J. E., Patridge, T. A., and Jackson, M. J. (2004). Release of reactive oxygen and nitrogen species from contracting skeletal muscle cells. Free Rad. Biol. Med. 37, 1064-1072. doi: 10.1016/j.freeradbiomed.2004.06.026

Peng, Y.-J., Nanduri, J., Yuan, G., Wang, N., Deneris, E., Pendyala, S., et al. (2009). NADPH oxidase is required for the sensory plasticity of the carotid body by chronic intermittent hypoxia. J. Neurosci. 29, 4903-4910. doi: 10.1523/JNEUROSCI.4768-08.2009

Peng, Y. J., and Prabhakar, N. R. (2003). Reactive oxygen species in the plasticity of respiratory behavior elicited by chronic intermittent hypoxia. J. Appl. Physiol. 94, 2342-2349.

Petrof, B. J., Pack, A. I., Kelly, A. M., Eby, J., and Hendricks, J. C. (1994). Pharyngeal myopathy of loaded upper airway in dogs with sleep apnea. J. Appl. Physiol. 76, $1746-1752$.

Pigeolet, E., C. P., Houbion, A., Lambert, D., Michiels, C., Raes, M., Zachary, M. D., et al. (1990). Glutathione peroxidase, superoxide dismutase, and catalase inactivation by peroxides and oxygen derived free radicals. Mech. Ageing Dev. 51, 283-297. doi: 10.1016/0047-6374(90)90078-T

Prabhakar, N. R. (2001). Oxygen sensing during intermittent hypoxia: cellular and molecular mechanisms. J. Appl. Physiol. 90, 1986-1994.

Raghuraman, G., Rai, V., Peng, Y. J., Prabhakar, N. R., and Kumar, G. K. (2009). Pattern-specific sustained activation of tyrosine hydroxylase by intermittent hypoxia: role of reactive oxygen species-dependent downregulation of protein phosphatase 2A and upregulation of protein kinases. Antiox. Redox Signal. 11, 1777-1789. doi: 10.1089/ars.2008.2368

Ray, A. D., Magalang, U. J., Michlin, C. P., Ogasa, T., Krasney, J. A., Gosselin, L. E., et al. (2007). Intermittent hypoxia reduces upper airway stability in lean but not obese Zucker rats. Am. J. Physiol. Regu. Integr. Comp. Physiol. 293, R372-R378. doi: 10.1152/ajpregu.00038.2007

Reid, M. B. (2001). Plasticity in skeletal, cardiac, and smooth muscle: invited review: redox modulation of skeletal muscle contraction: what we know and what we don't. J. Appl. Physiol. 90, 724-731.

Shan, X., Chi, L., Ke, Y., Luo, C., Qian, S., Gozal, D., et al. (2007). Manganese superoxide dismutase protects mouse cortical neurons from chronic intermittent hypoxia-mediated oxidative damage. Neurobiol. Dis. 28, 206-215. doi: 10.1016/j.nbd.2007.07.013

Sharma, S. D., Raghuraman, G., Lee, M. S., Prabhakar, N. R., and Kumar, G. K. (2009). Intermittent hypoxia activates peptidylglycine alpha-amidating monooxygenase in rat brain stem via reactive oxygen species-mediated proteolytic processing. J. Appl. Physiol. 106, 12-19. doi: 10.1152/japplphysiol.90702.2008

Shortt, C. M., Fredsted, A., Chow, H. B., Williams, R., Skelly, J. R., Edge, D., et al. (2014). Reactive oxygen species mediated diaphragm fatigue in a rat model of chronic intermittent hypoxia. Exp. Physiol. 99, 688-700. doi: 10.1113/expphysiol.2013.076828

Shortt, C. M., and O'Halloran, K. D. (2014). Hydrogen peroxide alters sternohyoid muscle function. Oral Dis. 20, 162-170. doi: 10.1111/odi.12084

Skelly, J. R., Bradford, A., Jones, J. F., and O'Halloran, K. D. (2010). Superoxide scavengers improve rat pharyngeal dilator muscle performance. Am. J. Respir. Cell Mol. Biol. 42, 725-731. doi: 10.1165/rcmb.2009-0160OC

Skelly, J. R., Edge, D., Shortt, C. M., Jones, J. F. X., Bradford, A., and O'Halloran, K. D. (2012a). Tempol ameliorates pharyngeal dilator muscle dysfunction in a rodent model of chronic intermittent hypoxia. Am. J. Respir. Cell Mol. Biol. 46, 139-148. doi: 10.1165/rcmb.20110084OC
Skelly, J. R., Rowan, S. C., Jones, J. F., and O'Halloran, K. D. (2012b). Upper airway dilator muscle weakness following intermittent and sustained hypoxia in the rat: effects of a superoxide scavenger. Physiol. Res. 62, 187-196.

Souvannakitti, D., Nanduri, J., Yuan, G., Kumar, G. K., Fox, A. P., and Prabhakar, N. R. (2010). NADPH oxidase-dependent regulation of T-Type $\mathrm{Ca}^{2+}$ channels and ryanodine receptors mediate the augmented exocytosis of catecholamines from intermittent hypoxia-treated neonatal rat chromaffin cells. J. Neurosci. 30, 10763-10772. doi: 10.1523/JNEUROSCI.2307-10.2010

Sun, Q.-A., Hess, D. T., Nogueira, L., Yong, S., Bowles, D. E., Eu, J., et al. (2011). Oxygen-coupled redox regulation of the skeletal muscle ryanodine receptor$\mathrm{Ca}^{2+}$ release channel by NADPH oxidase 4. Proc. Natl. Acad. Sci. U.S.A. 108, 16098-16103. doi: 10.1073/pnas.1109546108

van der Poel, C., Edwards, J. N., Macdonald, W. A., and Stephenson, D. G. (2007). Mitochondrial superoxide production in skeletal muscle fibers in the rat and decreased fiber excitability. Am. J. Physiol. Cell Physiol. 292, C1353-C1360. doi: 10.1152/ajpcell.00469.2006

Veasey, S. C., Zhan, G., Fenik, P., and Pratico, D. (2004). Long-term intermittent hypoxia: reduced excitatory hypoglossal nerve output. Am. J. Respir. Crit. Care Med. 170, 665-672. doi: 10.1164/rccm.200403-261OC

Verstraeten, E. (2007). Neurocognitive effects of obstructive sleep apnea syndrome. Curr. Neurol. Neurosci. Rep. 7, 161-166. doi: 10.1007/s11910-007-0012-8

Xia, R., Webb, J. A., Gnall, L. L., Cutler, K., and Abramson, J. J. (2003). Skeletal muscle sarcoplasmic reticulum contains a NADH-dependent oxidase that generates superoxide. Am. J. Physiol. Cell Physiol. 285, C215-C221. doi: 10.1152/ajpcell.00034.2002

Yuan, G., Adhikary, G., McCormick, A. A., Holcroft, J. J., Kumar, G. K., and Prabhakar, N. R. (2004). Role of oxidative stress in intermittent hypoxiainduced immediate early gene activation in rat PC12 cells. J. Physiol. 557, 773-783. doi: 10.1113/jphysiol.2003.058503

Yuan, G., Khan, S. A., Luo, W., Nanduri, J., Semenza, G. L., and Prabhakar, N. R. (2011). Hypoxia-inducible factor 1 mediates increased expression of NADPH oxidase-2 in response to intermittent hypoxia. J. Cell. Physiol. 226, 2925-2933. doi: $10.1002 /$ jcp. 22640

Zhou, W. E. I., Li, S., Wan, N., Zhang, Z., Guo, R. U. N., and Chen, B. (2012). Effects of various degrees of oxidative stress induced by intermittent hypoxia in rat myocardial tissues. Respirology 17, 821-829. doi: 10.1111/j.14401843.2012.02157.x

Conflict of Interest Statement: The authors declare that the research was conducted in the absence of any commercial or financial relationships that could be construed as a potential conflict of interest.

Received: 27 November 2014; accepted: 10 January 2015; published online: 30 January 2015.

Citation: Williams R, Lemaire P, Lewis P, McDonald FB, Lucking E, Hogan S, Sheehan $D$, Healy V and O'Halloran KD (2015) Chronic intermittent hypoxia increases rat sternohyoid muscle NADPH oxidase expression with attendant modest oxidative stress. Front. Physiol. 6:15. doi: 10.3389/fphys.2015.00015

This article was submitted to Striated Muscle Physiology, a section of the journal Frontiers in Physiology.

Copyright $\odot 2015$ Williams, Lemaire, Lewis, McDonald, Lucking, Hogan, Sheehan, Healy and O'Halloran. This is an open-access article distributed under the terms of the Creative Commons Attribution License (CC BY). The use, distribution or reproduction in other forums is permitted, provided the original author(s) or licensor are credited and that the original publication in this journal is cited, in accordance with accepted academic practice. No use, distribution or reproduction is permitted which does not comply with these terms. 